\title{
APRENDIZAGEM SIGNIFICATIVA NO ENSINO DE CIÊNCIAS CONTÁBEIS: UM ESTUDO EM UMA INSTITUIÇÃO DE ENSINO DE MINAS GERAIS
}

\section{SIGNIFICANT LEARNING IN THE TEACHING OF ACCOUNTING SCIENCES: A STUDY IN AN INSTITUTION OF MINAS GERAIS}

0 artigo foi aprovado e apresentado no IX Congresso Nacional de Administração e Contabilidade (AdCont), realizado de 24 a 26/11/2018, no Rio de Janeiro (RJ).

\begin{abstract}
RESUMO
Este trabalho descreve a utilização da teoria da Aprendizagem Significativa no ensino de Ciências Contábeis de uma Instituição de Ensino Superior (IES) de Minas Gerais. Por meio da disciplina denominada "Programa de Ação Social (PAS)", inserida no currículo do curso de Ciências Contábeis estudado, foi possível uma aplicação prática de conteúdos e conceitos contábeis ao desenvolver projetos focados na comunidade local. A pesquisa caracterizou-se por um estudo descritivo e qualitativo. Os resultados mostraram que a disciplina PAS favoreceu a reformulação do conceito "sala de aula", desfazendo-se da crença de que aprender é uma atividade passiva. Um aspecto relevante neste processo foi a contribuição para a formação cidadã. Apesar dessas instituições beneficiadas não visarem o lucro, elas precisam ter uma boa gestão para melhor aproveitamento dos recursos e, consequentemente, maiores benefícios para a sociedade. A adoção dos controles internos e a apuração dos custos nessas instituições do terceiro setor proporcionam uma sustentabilidade econômica que oportunizam a continuidade de suas operações e ao cumprimento de suas missões. Assim, a comunidade local se beneficiou, com o aproveitamento máximo dos recursos dessas instituições e com a ampliação das ações sociais. Além disso, constatou-se uma evolução na desenvoltura dos alunos por meio da elaboração do relatório final.
\end{abstract}

Palavras-chave: Aprendizagem Significativa. Ensino. Ciências Contábeis.

\begin{abstract}
This study describes the use of the Meaningful Learning Theory in the Accounting Science teaching of an IES of Minas Gerais. Through the discipline called "Social Action Program (PAS)", inserted in the curriculum of the Accounting Science course studied, it was possible a practical application of contents and accounting concepts when developing projects focused on the local community. The research was characterized by a descriptive and qualitative study. The results showed that the PAS discipline favored the reformulation of the concept "classroom", undoing the belief that learning is a passive activity. A relevant aspect in this process was the contribution to citizen formation. Although these benefited institutions are not aimed at profit, they need to have good management to make better use of resources and, consequently, greater benefits to society. The adoption of internal controls and the determination of costs in these third sector institutions provide economic sustainability that enables the continuity of their operations and the fulfillment of their missions. Thus, the local community benefited from the maximum use of the resources of these institutions and the expansion of social actions. In addition, there was an evolution in student resourcefulness through the preparation of the final report.
\end{abstract}

Keywords: Significant Learning. Teaching. Accounting Sciences.
Lívia Maria de Pádua Ribeiro Doutora em Administração pela Universidade Federal de Lavras (UFLA). Mestre em Administração pela Universidade Federal de Lavras (UFLA) Graduada em Ciências Contábeis pela Universidade Federal de Minas Gerais (UFMG). Docente do Programa de Pós-Graduação em Administração no Centro Federal de Educação Tecnológica de Minas Gerais (PPGA CEFET-MG). Contato: Av. Amazonas, 7675, Bairro Nova Gameleira, Belo Horizonte, MG, CEP 30.510-000, E-mail: liviapadua@cetetmg.br
João Eduardo Ribeiro
Doutorando em Administração pela Universidade Federal de Minas Gerais (UFMG). Mestre em Administração pelo Centro Federal de Educação Tecnológica de Minas Gerais (CEFET-MG). Graduado em Ciências Contábeis pela Universidade Federal de Viçosa (UFV). Contato: Av. Pres. Antônio Carlos, 6627 - Pampulha, Belo Horizonte, MG, CEP 31270-901, E-mail: joaoribeiro.cco@gmail.com

\section{Uajará Pessoa Araújo}
Doutor em Administração pela Universidade Federal de Lavras (UFLA) e em Engenharia de Produção pela Universidade de São Paulo (USP). Mestre em Administração pela Universidade Federal da Bahia (UFBA) Graduação em Ciências Econômicas pela Universidade Federal de São João Del-Rei (UFSJ). Docente do Programa de Pós-Graduação em Administração no Centro Federal de Educação Tecnológica de Minas Gerais (PPGA/ CEFET-MG). Contato: Av. Amazonas, 7675, Bairro Nova Gameleira, Belo Horizonte, MG, CEP 30.510-000, E-mail: uajara@cefetmg.br 


\section{INTRODUÇÃO}

Os tempos mudaram: a globalização do mercado, a competitividade das empresas e os avanços tecnológicos demandam por profissionais ativos, dinâmicos e criativos. Isto faz com que as instituições de ensino superior realizem um debate sobre a formação do profissional do futuro, buscando uma maior reflexão sobre adequação do curso ao mundo atual e a compatibilidade com o ambiente de negócio da contemporaneidade.

Outro aspecto relevante para a formação do profissional, além da qualificação técnica e postura no ambiente de trabalho, é a sua consciência cidadã. A sociedade necessita de profissionais críticos que sejam capazes de contribuir para a transformação social visando um mundo mais ético e melhor para se viver. Dentro deste contexto, surge um novo paradigma educacional, priorizando uma aprendizagem que proporcione a crítica, a criação, a construção e a transformação (Zuffo \& Behrens, 2009). Neste sentido, evidencia-se a Aprendizagem Significativa (Ausubel, 1963) ao invés de uma aprendizagem mecânica e memorizada, que se confirma com as publicações de Marques e Praia (2000), Carvalho, Porto e Belhot (2001), Marks e Mclntosh (2006), Bledsoe e Flick (2012), Esteban-Guitart, Serra e Vila (2017), dentre outras.

O ensino não deve ser focado apenas na transmissão de conteúdo, em que o professor desempenha o papel de mero executor de programas e em que o aluno aprende passivamente. Para Freire (1996), ensinar não é transferir conhecimento, mas criar as possibilidades para a sua própria construção. Ensinar é preparar o caminho para a total autonomia de quem aprende, é fazer cidadão consciente de seus deveres e direitos.

Diante das transformações do cenário contemporâneo, em que o ambiente organizacional é caracterizado como competitivo, incerto, imprevisível, dinâmico, complexo e desafiador; as Diretrizes Curriculares do Brasil para os cursos de graduação em Ciências Contábeis consubstanciam a mudança dos programas de formação, permitindo a Instituição de Ensino Superior (IES) compor um currículo com mais autonomia e liberdade, com intuito de adequá-lo às exigências do mercado e do mundo contemporâneo.

Nesse sentido, este estudo tem como objetivo principal, descrever os recursos e metodologias relativos à teoria da Aprendizagem Significativa utilizados no ensino de Ciências Contábeis de uma IES de Minas Gerais. Por meio da disciplina denominada "Programa de Ação Social (PAS)" inserida no currículo do curso de Ciências Contábeis estudado, foi possível realizar uma aplicação prática de conteúdos, conceitos e de técnicas contábeis ao desenvolver projetos focados na comunidade local. Como objetivos específicos, este estudo buscou apresentar as etapas do funcionamento da disciplina PAS; identificar as competências e habilidades desenvolvidas pelos discentes nesta disciplina; além de contribuir para uma reflexão acerca do processo ensino-aprendizagem.

Assim, o estudo visou responder aos seguintes questionamentos: Quais foram as competências e habilidades desenvolvidas pelos discentes com a utilização da Teoria da Aprendizagem Significativa no ensino de Ciências Contábeis de uma IES de Minas Gerais? Quais foram as etapas para o funcionamento da disciplina PAS inserida na grade curricular no curso de Ciências Contábeis de uma IES de Minas Gerais?

Esta disciplina não se baseia somente em aulas expositivas, mas na execução de um trabalho prático realizado por pequenos núcleos de alunos - grupos tutoriais - fortemente impregnados de autogestão, o que requer ativa participação do discente. Caracteriza-se, portanto, pelo envolvimento do aluno em pesquisa, vivência da prática e trabalho colaborativo grupal. O propósito da disciplina PAS foi promover ações extensionistas capazes de vislumbrar a integração acadêmica com a sociedade. Buscou-se aplicar os conhecimentos acadêmicos na comunidade local. A disciplina PAS buscou orientar duas instituições sem fins lucrativos na apuração dos seus custos, na elaboração dos seus controles internos e na utilização de ferramentas gerenciais proporcionando uma gestão transparente e eficiente.

Pode-se dizer que a disciplina PAS, inserida na grade curricular do curso de Ciências Contábeis da IES base deste estudo, contribuiu para a orientação de duas instituições sem fins lucrativos em sua gestão administrativa e contábil a fim de proporcionar-lhes melhor desempenho. O programa envolveu conteúdo das disciplinas de Contabilidade de Custos, Controladoria e Auditoria. O desenvolvimento destes projetos (apuração de custos e diagnósticos dos controles internos das instituições) foi realizado pelos alunos sob a supervisão do professor da disciplina PAS com o apoio dos professores das disciplinas Contabilidade de Custos, Controladoria e Auditoria. Durante o processo discente foi estimulado a desenvolver atitudes de autoconfiança, autonomia, responsabilidade, agilidade, estudo permanente, colaboração, compromisso, tolerância e respeito.

Este estudo é importante, uma vez que apresenta uma possibilidade de desenvolver metodologias da Aprendizagem Significativa no ensino contábil e também por proporcionar diversas reflexões sobre o processo ensino-aprendizagem e a formação profissional.

\section{REFERENCIAL TEÓRICO}

Nesta seção foi evidenciado o novo paradigma educacional ressaltando a importância da Teoria da Aprendizagem Significativa no ensino. Além disso, foram apresentadas as diretrizes curriculares do Brasil para os cursos de graduação, enfatizando o curso de Ciências Contábeis. 


\subsection{Novo Paradigma Educacional}

Uma das características dominantes no novo saber e dos novos perfis profissionais exigidos pelo século XXI é a capacidade de se transitar entre diversos campos do conhecimento, no sentido de projetar aplicações rápidas para resolução de problemas (Brandão, 2008).

Para que a formação do profissional seja satisfatória, os cursos não mais poderão permanecer oferecendo recursos humanos "despreparados" para enfrentar o mercado atual, ou seja, formar profissionais sem aptidões, capacidades, habilidades e domínios necessários às exigências sociais, políticas, econômicas, ambientais e organizacionais do mundo contemporâneo. Para que os profissionais atendam a nova realidade é necessário um novo paradigma educacional (Escrivão Filho \& Ribeiro, 2008; Zuffo \& Behrens, 2009).

Os aspectos históricos e culturais são relevantes para compreender os paradigmas. No passado, com a origem da ciência moderna, o paradigma predominante era o newtoniano cartesiano, que possuía uma visão positivista do universo. O paradigma newtoniano cartesiano caracterizava-se por reconhecer a relevância das propriedades quantificáveis da matéria e por jamais defender alguma coisa como verdade sem evidência concreta. Assim, a educação foi orientada por este pensamento, que se baseava na reprodução e fragmentação do conhecimento, em que a prática pedagógica era centrada em: escutar, ler, decorar e repetir (Behrens, 2009).

A partir do início do século XX, o paradigma newtoniano cartesiano vem cedendo espaço ao denominado paradigma da complexidade. A descoberta da mecânica quântica fez com que a sociedade tivesse a necessidade de ter a visão do todo, de realizar conexão, redes e inter-relacionamentos, ao invés de se ater a um conhecimento fragmentado. $\mathrm{O}$ acesso ao conhecimento se expande com o surgimento da internet e para atender ao novo paradigma exigem-se mudanças na metodologia de ensino. As escolas, faculdades e universidades vêm gradativamente abandonando uma aprendizagem mecanizada e adotando uma Aprendizagem Significativa, que contemple a reflexão, o envolvimento em trabalhos coletivos, o espírito de colaboração, dentre outras práticas que levem à transformação da realidade (Behrens, 2009).

Para Brunstein e Miguel (2007) o cenário em que se encontra a ciência indica que o conhecimento específico isolado não é mais suficiente para atender a complexidade dos fenômenos estudados. Moreira e Masini (2002) explicam que o conceito de Aprendizagem Significativa surgiu em 1963 com a teoria de David Ausubel. Posteriormente esta teoria foi gradativamente aperfeiçoada por outros autores. A teoria de David Ausubel fundamenta-se num modelo dinâmico, em que a verdadeira aprendizagem ocorre quando o aluno (re)constrói o conhecimento criando conceitos que possibilita criticar e reagir diante da realidade (Ausubel, 1963).

A Tabela 1 expõem, de acordo com Santos (2008), alguns comportamentos essenciais para o professor promover a Aprendizagem Significativa.

Tabela 1 - Comportamentos essenciais para o professor promover a Aprendizagem Significativa

\section{Comportamento essencial}

Parar de dar aulas

Parar de dar respostas

Procurar novas formas de desafiar os alunos

Perseguir a aprendizagem profunda

Parar de dar tantas instruções

Elevar a autoestima do aluno

Promover a interação entre os alunos

\section{Descrição}

No sentido de que o professor não tem nenhuma aula a "dar", mas sim a construir junto com o aluno. O papel do professor não é apresentar o "mundo pronto", pois, este não é o contexto atual. O mundo está em constante mudança e o aluno não pode ficar apenas escutando e memorizando as informações como se fosse um robô, o aluno deve ser estimulado a pensar, a agir, a fazer parte ativamente das aulas.

Respostas prontas impedem o aprendizado, aprender é fruto de esforço. O professor tem a função de gerar questionamentos e fazer com que o aluno tenha a necessidade das informações. Assim, haverá o interesse, a vontade, o desejo e a curiosidade para aprender.

Isto quer dizer apresentar novas práticas pedagógicas e metodologias de ensino. O professor tem um novo desafio com relação ao planejamento das aulas. Um conceito aprendido pode servir de parâmetro para a construção de novos conceitos.

A aprendizagem profunda está relacionada com a importância da compreensão do conteúdo, diferente da aprendizagem superficial que limita a cumprir uma determinada tarefa formulada pelo professor. $\mathrm{Na}$ aprendizagem superficial o conhecimento é isolado, o aluno não faz conexão e integração das informações com outros elementos.

Excessos de instruções geram a dependência dos alunos. É preciso orientar, passar instruções necessárias de forma que o aluno desenvolva a autonomia.

Faz parte do processo de aprendizagem valorizar o aluno, reforçar o que ele já sabe. O respeito e a confiança mútua são atitudes relevantes para o processo de uma Aprendizagem Significativa.

O aluno aprende na relação com os outros, a interação social é necessária em um processo de aprendizagem. Existem trocas de ideias, reflexões sobre opiniões de colegas e oportunidades de construção de algo novo. É lógico que existe limite, a interação não pode promover dispersão e perda de foco, caso contrário, a aula deixa de proporcionar o aprendizado.

Fonte: Santos (2008). 
Guimarães, Cittadin, Giassi, Guimarães Filho e Bristot (2016) esclarecem que diante o mercado de trabalho contemporâneo, o curso de Ciências Contábeis requer uma Aprendizagem Significativa em que o discente desenvolva a capacidade crítica e a reflexão do conteúdo. Assim, com intenção de proporcionar uma Aprendizagem Significativa são aplicadas algumas práticas pedagógicas e metodologias ativas. Alguns estudos evidenciam o uso dessas práticas e metodologias no curso de Ciências Contábeis, como pode ser visto nos trabalhos de Martins, Espejo e Frezatti (2015) que apresentam a experiência do uso problem-based learnig no ensino de contabilidade gerencial; Biavatti, Mazzuco e Wronski (2018) que tratam das técnicas de diálogos sucessivos no ensino contábil; Vasconcelos e Araújo (2017) que discutem sobre o benefício do uso de mapas conceituais em disciplinas de contabilidade; Pereira e Silva (2018) que adotaram a aprendizagem cooperativa como estratégia de ensino para a contabilidade; dentre outros.

As constantes mudanças no mercado de trabalho e no processo de conhecimento requer inovação e surgimento de diversas metodologias que reforçam a necessidade da Aprendizagem Significativa. Diante esse novo paradigma educacional, as Diretrizes Curriculares para os cursos de graduação no Brasil tendem a garantir que as IES tenham flexibilidade curricular e liberdade na construção de seus projetos pedagógicos, para adequá-los às exigências do mundo contemporâneo.

\subsection{As Diretrizes Curriculares no Brasil para os Cursos de Graduação}

A partir de 1996, com a criação da nova Lei de Diretrizes e Bases da Educação Nacional, o Brasil vivenciou um movimento de reformas no que diz respeito à reorganização da educação em todos os níveis. Foi instituído um novo modelo curricular, não mais baseado nos Currículos Mínimos, mas sim nas Diretrizes Curriculares (Fronza, 2009).

As Diretrizes Curriculares Nacionais (DCNs) são normas obrigatórias fixadas pelo Conselho Nacional de Educação (CNE) que tem como propósito orientar o planejamento curricular do sistema escolar. As DCNs consubstanciam a mudança da figura do Currículo Mínimo, que se caracterizava pela rigidez na sua configuração formal, não permitindo o alcance da qualidade desejada em sua contextualização de espaço e tempo; para um novo modelo que se define pela autonomia e liberdade de cada instituição de ensino em compor seu currículo e suas formas de operacionalização (Menezes \& Santos, 2002).

A postura do governo brasileiro regulador ao invés da predominância do paternalismo e assistencialismo foi fundamental para a inserção das DCNs. Com o passar do tempo o governo brasileiro vai transferindo a responsabilidade de organização e gestão da educação também para outros atores privados. Não quer dizer que o governo brasileiro esteja se retirando da educação, o que ocorre é que o mesmo está adotando um novo papel: o de regulador e avaliador. Assim, o governo brasileiro define orientações e metas para ser atingidas, criando um sistema de monitoramento e avaliação para saber se os resultados desejados foram alcançados. A regulação é mais flexível na definição de processos e rígida na avaliação da eficiência e eficácia dos resultados (Barroso, 2005).

À vista disso, neste novo contexto se ganha uma maior flexibilidade com a criação das Diretrizes Curriculares e simultaneamente forma-se um aparato de controle para avaliar os resultados dos cursos de graduação no Brasil (Fronza, 2009). Tem-se como exemplo, o Exame Nacional de Desempenho de Estudantes (ENADE), dentre outras avaliações realizadas pelo Ministério da Educação (MEC).

Segundo Fronza (2009) o Currículo Mínimo inibia a inovação e a criatividade das instituições de ensino, uma vez que estabelecia nacionalmente os componentes curriculares e os conteúdos obrigatórios. As DCNs, por sua vez, foram instituídas para promover a flexibilidade das instituições do ensino superior na elaboração dos seus projetos pedagógicos, podendo ser confirmado no Parecer 67/2003 do CNE:

“(...) as Diretrizes Curriculares Nacionais ensejam a flexibilização curricular e a liberdade de as instituições elaborarem seus projetos pedagógicos para cada curso segundo uma adequação às demandas sociais e do meio e aos avanços científicos e tecnológicos, conferindo-lhes uma maior autonomia na definição dos currículos plenos dos seus cursos;

(...) as Diretrizes Curriculares Nacionais pretendem preparar um profissional adaptável a situações novas e emergentes;

(...) as Diretrizes Curriculares Nacionais se propõem ser um referencial para a formação de um profissional em permanente preparação, visando uma progressiva autonomia profissional e intelectual do aluno, apto a superar os desafios de renovadas condições de exercício profissional e de produção de conhecimento”; (Conselho Nacional de Educação, 2003).

Currículos mais flexíveis podem promover interdisciplinaridade entre os conteúdos; tempos e espaços diversificados para a efetivação do processo educativo; e desenvolvimento de competências e habilidades para uma melhor formação do profissional para o mercado de trabalho atual. Diante a esta responsabilidade que foi conferida às instituições de ensino superior é relevante realizar uma reflexão: “a quem esta flexibilização está servindo?” (Fronza, 2009, p. 56). Se a flexibilização dos currículos não tem como objetivo servir ao processo educativo, promovendo uma Aprendizagem Significativa ao invés de uma aprendizagem mecanizada, ela poderá ter um efeito contrário e ser entendida e praticada de maneira a prejudicar a formação dos profissionais. A flexibilidade não pode ser usada como mero adestramento do ser humano às necessidades do mercado capitalista ou para visar o aumento dos resultados financeiros de uma IES do setor privado (Fronza, 2009). 


\section{PROCEDIMENTOS METODOLÓGICOS}

Para a realização deste estudo foi adotado uma pesquisa descritiva de abordagem qualitativa. A abordagem qualitativa é a mais propícia para nortear este estudo, uma vez que o foco está na compreensão dos fatos e não na pretensão de medir ou enumerar (Martins \& Lintz, 2007). Segundo Merriam (2002), a investigação qualitativa é indicada para os casos de estudos de inovações educacionais. Para Oliveira (2004, p.114) "o estudo descritivo possibilita o desenvolvimento de um nível de análise em que se permite identificar as diferentes formas dos fenômenos, sua ordenação e classificação. Descrever significa identificar, relatar, comparar, entre outros aspectos".

A construção de evidências foi realizada a partir da participação em reuniões, que tiveram como propósito o desenvolvimento da disciplina PAS em cursos de graduação de uma IES no Brasil. Além disso, foram realizadas leituras e análises dos manuais e diretrizes elaboradas para a concretização da disciplina PAS; e entrevistas informais com o professor e alunos da referida disciplina durante o semestre de sua realização.

O pesquisador neste processo funcionou como observador participante, apesar de não ser o professor da disciplina, participou como supervisor de todas as disciplinas PAS da IES em estudo. Contudo, enfatizou nessa pesquisa a disciplina PAS do curso de Ciências Contábeis por ter maior conhecimento da área. Os demais autores do artigo não foram observadores participantes, contudo, por serem pesquisadores acadêmicos, docente e discente contribuíram para a discussão deste estudo. A natureza sistemática das observações e conduta interveniente do pesquisador confere a esse processo a condição de observação participante. Conforme Haguette (2003), a observação participante demanda a presença do pesquisador nas atividades do grupo investigado e ainda requer em muitos casos o compartilhamento de significados e a inserção de mudanças sociais, podendo aproximar essa técnica do fato denominado de pesquisa-ação. Por isso, nesta pesquisa, pode-se considerar que a técnica utilizada foi a observação participante; o que pode ser afirmado com a vivência do planejamento, do desenvolvimento, dos resultados obtidos com a disciplina PAS e discussões sobre o assunto.

A disciplina PAS possui uma carga horária de oitenta horas no semestre, ocorrendo dois encontros semanais; além das visitas realizadas nas duas instituições sem fins lucrativos (associação e organização não governamentais) da comunidade local. O propósito desta disciplina foi promover ações extensionistas capazes de vislumbrar a integração acadêmica com a sociedade, buscando aplicar os conhecimentos acadêmicos na comunidade local, além de contribuir para a formação profissional dos alunos do curso de Ciências Contábeis. A disciplina PAS analisada neste estudo foi inserida no quinto período do curso, onde os alunos já haviam cursado a disciplina de Contabilidade de Custos, e estavam cursando as disciplinas de Controladoria e Auditoria. A disciplina PAS contou com vinte e cinco alunos matriculados. Para o desenvolvimento da disciplina foram formados oito grupos com quatro alunos; quatro grupos ficaram responsáveis pela associação e os outros quatro grupos pela organização não governamental. Dentro destes quatro grupos, dois são responsáveis pelo levantamento dos custos e os outros dois pelos controles internos. Os grupos precisam se relacionar para o desenvolvimento do produto final.

As instituições beneficiadas foram organizações que demandavam de controles e orientações na área administrativa e contábil. As duas instituições promovem ações sociais e educativas na comunidade local.

\section{ANÁLISE E INTERPRETAÇÃO DOS RESULTADOS}

As Diretrizes Curriculares do Brasil orientam os cursos de graduação a estimular a conexão da teoria com a prática, valorizando a pesquisa e a participação em atividades de extensão (Fronza, 2009). Considera-se o ensino, pesquisa e extensão, fundamentais para o processo de aprendizagem e construção do conhecimento. Diante a flexibilidade dos currículos e do estímulo a efetivação das atividades de ensino, pesquisa e extensão foi criada a disciplina PAS, proporcionando ações sociais por meio da aplicação prática de conteúdos do curso na comunidade local. Foram escolhidas duas instituições sem fins lucrativos (associação e organização não governamentais) da comunidade local e acordadas com elas, para que os alunos sob a supervisão do professor realizassem serviços gratuitos aplicando a prática de conteúdos do curso de Ciências Contábeis. No produto final os alunos apresentaram os custos da instituição sem fins lucrativos, os controles internos e as ferramentas gerenciais relevantes para uma gestão transparente e eficiente.

A disciplina PAS foi inserida no curso de Ciências Contábeis no ano de 2010 e permanece até os dias atuais. No início, os professores e alunos sentiram-se receosos com o desafio proposto, contudo, depois de muitos anos percebe-se que a prática que é aplicada na comunidade local é também muito enriquecedora para a formação do aluno como profissional e como cidadão. Para o desenvolvimento desta disciplina são realizadas diversas reuniões com o supervisor das disciplinas PAS, coordenadores de cursos e professores das disciplinas de todos os cursos de graduação da IES. Essa reunião é realizada para verificar a demanda da comunidade local. Cada semestre que a disciplina é oferecida atende-se uma demanda diferente, fazendo-se uso da teoria Aprendizagem Significativa, no sentido de existir um novo contexto onde os saberes são (re)construídos. Nessas reuniões também é discutido e planejado o funcionamento da disciplina conforme as diretrizes propostas pela IES.

Ao iniciar a disciplina, as primeiras aulas acontecem em formato de reuniões, para discutir e planejar como as demandas serão atendidas e o cronograma para a execução das atividades. Nesse momento é elaborado um manual para a disciplina, posto que os alunos devem apresentar um produto para as duas instituições sem fins lucrativos da comunidade local ao terminar o semestre. 
A IES deste estudo possui um regime semestral para o encerramento das disciplinas. A disciplina PAS conta com uma carga horária mínima de oitenta horas, correspondendo a dois encontros semanais. No primeiro encontro semanal são realizados planejamentos e orientações juntamente com o professor. No segundo encontro são desenvolvidas as atividades práticas ou estudos do grupo. O aluno não pode desenvolver o projeto individualmente, a avaliação é processual ao longo do semestre e a apresentação do produto final e resultados contam com a participação de todos os alunos envolvidos. A Tabela 2 evidencia as atribuições dos alunos e do professor da disciplina.

Tabela 2 - Atribuições do Professor e Alunos Matriculados na Disciplina PAS

\begin{tabular}{|c|c|}
\hline Atribuições do Professor & Atribuições dos Alunos \\
\hline $\begin{array}{l}\text { - Planejar e acompanhar o desenvolvimento da disciplina PAS e } \\
\text { as atividades a ser realizada na comunidade local (associação e } \\
\text { organização não governamentais); } \\
\text { - Promover questionamentos sobre as atividades, motivar } \\
\text { e instigar os alunos a pesquisar e estudar, acompanhar o } \\
\text { cronograma de execução das atividades; } \\
\text { - Articular as ações da Instituição do Ensino Superior (IES) } \\
\text { com a comunidade local no sentido de viabilizar e cumprir o } \\
\text { objetivo da disciplina; } \\
\text { - Definir, junto ao supervisor da IES e coordenador do curso, as } \\
\text { instituições (associações e organizações não governamentais) } \\
\text { que serão prestados os serviços gratuitos. Estabelecer contatos } \\
\text { com os representantes das instituições para realizar a visita } \\
\text { com os alunos; } \\
\text { - Avaliar as atividades ao longo do semestre e formar uma banca } \\
\text { examinadora formada por docentes para a avaliação do produto } \\
\text { final e resultados obtidos no desenvolvimento do projeto. }\end{array}$ & $\begin{array}{l}\text { - Formar equipes para o desenvolvimento das atividades de } \\
\text { extensão; } \\
\text { - Aplicar os conhecimentos acadêmicos na comunidade } \\
\text { envolvida; } \\
\text { - Definir juntamente com o professor o cronograma para a } \\
\text { execução das atividades; } \\
\text { - Desenvolver as atividades conforme o cronograma validado } \\
\text { em sala de aula; } \\
\text { - Realizar pesquisas e estudos para desenvolver as atividades } \\
\text { de extensão; } \\
\text { - Levantar dados da instituição (associação e organização } \\
\text { não governamentais) para cumprir o objetivo da disciplina } \\
\text { (apuração dos custos e elaboração de controles internos) } \\
\text { - Participar dos eventos relacionados com as atividades de } \\
\text { extensão desenvolvidas na disciplina PAS; } \\
\text { - Apresentar o produto final para uma banca examinadora e } \\
\text { para os responsáveis pelas instituições beneficiadas. Apresentar } \\
\text { para o professor os resultados das atividades realizadas durante } \\
\text { o desenvolvimento da disciplina. }\end{array}$ \\
\hline
\end{tabular}

Fonte: Dados da pesquisa.

Para um melhor entendimento foram apresentadas as etapas do funcionamento da disciplina PAS.

\subsection{Planejamento}

A etapa de planejamento da disciplina PAS acontece no final do semestre anterior à realização das atividades a serem desenvolvidas e na primeira semana do semestre letivo, em dias previamente definidos para tal atividade. O programa a ser desenvolvido na disciplina deve respeitar os princípios norteadores da interdisciplinaridade e os projetos político-pedagógicos de cada curso, de tal forma que as ações estejam adequadamente articuladas com os temas e eixos temáticos de cada curso. Para a execução das atividades, o aluno deve utilizar conteúdo das disciplinas que já tenha cursado em períodos anteriores ou que estejam cursando no período, o que favorece a interdisciplinaridade.

Esta etapa consiste em reunião de planejamento entre o coordenador de curso e supervisor da IES com todos os professores envolvidos no PAS com o propósito de formar uma equipe de docentes integrada, capaz de suprir as necessidades técnicas necessárias para o desenvolvimento de ações sociais. Além disso, o supervisor das disciplinas PAS da IES e o coordenador do curso juntamente com o professor do PAS com o apoio da IES deve definir as instituições a serem beneficiadas pelo projeto, viabilizando a carta de intenções da mesma por escrito. Neste estudo, foram escolhidas duas instituições da comunidade local para serem beneficiadas: uma associação e uma organização não governamentais. As escolhas destas instituições se devem a carência na área administrativa e contábil. A IES divulga o trabalho gratuito a ser desenvolvido e as instituições cadastram-se para serem beneficiadas.

\subsection{Desenvolvimento do PAS}

Na etapa de desenvolvimento do PAS tem-se: a) a apresentação do objetivo da disciplina; b) a formação dos grupos e suas responsabilidades; c) a definição do cronograma conforme a proposta a ser cumprida; e d) a execução das atividades extensionistas.

Inicialmente, o professor apresenta aos alunos as instituições a serem beneficiadas pelo projeto e as possíveis carências que podem ser solucionadas ou minimizadas com a contribuição do curso de Ciências Contábeis. Como estas instituições disseram que não tinham conhecimento dos seus custos e questionava a sua gestão, a proposta acordada com os representantes das instituições foi levantar os seus custos e realizar um diagnóstico identificando quais os con- 
troles internos existentes em sua gestão. Após este diagnóstico, se a instituição demonstrou fragilidades, são elaborados os controles internos a serem adotados no seu dia-a-dia.

Em seguida, formam-se grupos de alunos para a realização das atividades. Os grupos devem utilizar leituras e textos indicados pelo professor para que a teoria possa ser utilizada nas ações. São realizadas visitas para coletar informações das instituições e posteriormente os dados são trabalhados em sala de aula, laboratório de informática e biblioteca. Os espaços para o desenvolvimento do PAS são os mais diversos, podendo contemplar todos os espaços dentro da IES e espaços extramuros (associação e organização não governamentais).

A definição do cronograma das atividades conforme a proposta a ser cumprida é realizada pelos alunos e professor. O cronograma contempla as ações a serem executadas e as avaliações processuais, além dos eventos relacionados com o PAS e a apresentação do produto final para a banca examinadora e posteriormente às instituições beneficiadas.

A execução das atividades extensionistas são de fato as visitas, o levantamento dos dados, a discussão e pesquisa para a apuração dos custos e elaboração dos controles internos. Ao final, cada grupo deve apresentar seus resultados e o produto final, e os relatórios a serem entregues para as duas instituições beneficiadas. Neste caso, foram formados oito grupos com quatro alunos; quatro grupos ficaram responsáveis pela associação e os outros quatro grupos pela organização não governamental. Dentro destes quatro grupos, dois são responsáveis pelo levantamento dos custos e os outros dois pelos controles internos. Os grupos precisam se relacionar para o desenvolvimento do produto final.

As atividades realizadas pelos alunos sob a supervisão do professor foram desenvolvidas conforme a demanda apresentada pelas duas instituições sem fins lucrativos beneficiadas na disciplina PAS: o levantamento dos custos e criação de controles internos. O sistema de custeio adotado foi o custeio pleno ou integral, que segundo Santos (1999) caracteriza-se pela apropriação de todas as despesas e custos aos produtos fabricados e serviços prestados, sejam, custos diretos e indiretos, fixos e variáveis. Para atender a demandas das duas instituições beneficiadas, as atividades foram organizadas e desenvolvidas nas seguintes fases expostas na Tabela 3.

Tabela 3 - Atividades organizadas e desenvolvidas por fases.

\begin{abstract}
Fase 1
Grupos responsáveis pelo levantamento de custos: a) Primeira fase: apresentação da proposta para levantamento dos custos; b) Segunda fase: levantamento do patrimônio (móveis, imóvel, veículos, máquinas, etc.) e realização dos cálculos referentes à depreciação conforme disciplina já cursada, como contabilidade gerencial; c) Terceira fase: levantamento dos gastos com mão-de-obra e de outros gastos, conforme disciplina de contabilidade de custos; e) Quarta fase: apuração do custo das instituições beneficiadas conforme o sistema de custeio pleno; f) Quinta fase: apresentação e discussão dos resultados pelos alunos. Essa fase é bastante significativa, é feito uma exposição dos relatórios e controles elaborados pelos alunos. Nesse momento são realizadas críticas e sugestões dos colegas e professor; g) Sexta fase: eventos com apresentações do resultado final da disciplina PAS pelos alunos para a entrega dos relatórios e controles internos para banca examinadora e posteriormente às instituições beneficiadas.
\end{abstract}

Fase 2

Grupos responsáveis pela criação dos controles internos: a) Primeira fase: estudo sobre controle interno e elaboração de um questionário para obtenção do diagnóstico das instituições; b) Segunda fase: aplicação de questionário, para identificar os controles existentes e controles que são necessários para as instituições. Nessa etapa foram feitos uso das disciplinas de auditoria e controladoria, além da vivência e experiência dos alunos; c) Terceira fase: levantamento dos resultados e apresentação da proposta identificando quais os controles internos devem ser reforçados e criação dos controles inexistentes; d) Quarta fase: elaboração dos controles internos conforme diagnóstico; e) Quinta fase e Sexta fase se repetem conforme o grupo responsável pelo levantamento de custos.

Fonte: Dados da pesquisa.

O desenvolvimento dessas fases foi ao encontro com a utilização da Teoria de Aprendizagem Significativa, criada por Ausubel (1963), além de evidenciar a importância do conhecimento interdisciplinar, o que corrobora com a afirmação de Brunstein e Miguel (2007), ao explicar que conhecimento específico isoladamente não é mais suficiente para atender a complexidade dos fenômenos estudados. Essas atividades desenvolvidas na disciplina PAS promoveram a reciprocidade de responsabilidades, a interação do conteúdo das disciplinas do curso e a vivência da realidade.

\subsection{Avaliação Processual}

O aluno é avaliado durante todo o processo de desenvolvimento de habilidades e competências que possam contribuir para a sua formação. É essencial que nesta avaliação o professor esteja fornecendo um feedback sobre o desempenho do aluno, sendo assim, o aluno poderá evoluir na sua formação como profissional e cidadão. Neste processo é avaliada a desenvoltura do aluno, a capacidade de trabalhar em grupo, de argumentar e criticar, a inovação e a resolução de conflitos. Ao longo do semestre, o desenvolvimento do PAS é avaliado conforme Tabela 4: 
Tabela 4 - Distribuição de Pontos na Avaliação Processual

\begin{tabular}{l|l}
\hline Atividades & Pontos \\
\hline $\begin{array}{l}\text { Livres. Cabe ao professor definir sua avaliação. O professor avalia durante o semestre o } \\
\text { desenvolvimento das habilidades e competências do aluno. }\end{array}$ & 30 pontos \\
$\begin{array}{l}\text { Relatório parcial da execução do projeto } \\
\text { Relatório final da execução do projeto (impresso e completo) }\end{array}$ & 25 pontos \\
$\begin{array}{l}\text { Participação do evento com a apresentação oral do produto final (Relatório contendo o di- } \\
\text { agnóstico das instituições beneficiadas e a apuração dos custos) para a banca examinadora. } \\
\text { A nota é uma média da avaliação dos professores da banca examinadora (Evento 1) }\end{array}$ & 10 pontos \\
$\begin{array}{l}\text { Participação do evento e apresentação oral para a entrega dos relatórios aos re- } \\
\text { sponsáveis das instituições beneficiadas (Evento 2) }\end{array}$ & 10 pontos
\end{tabular}

Fonte: Dados da pesquisa.

As principais habilidades e competências que os alunos desenvolveram nesta disciplina conforme relatos do professor, alunos e manual da disciplina PAS: A capacidade de fazer uso da linguagem contábil nas discussões em grupos e na comunicação com os representantes das instituições beneficiadas; a proficiência em selecionar e assumir prioridades dentro das limitações de tempo e espaço; a visão sistêmica, holística e interdisciplinar da atividade contábil; o uso do raciocínio lógico e crítico-analítico ao executar as atividades; a capacidade de lidar com conflitos; de identificar problemas e propor soluções viáveis; a articulação, motivação e liderança de equipes multidisciplinares para a captação de dados e para a elaboração de planilhas e relatórios.

O relatório final contemplou todo o diagnóstico do controle interno das instituições beneficiadas com a disciplina, além da apuração dos custos e modelos de controles internos a ser utilizados no cotidiano dessas organizações. Em uma das instituições estudadas inexistia o controle do patrimônio, então, os alunos fizeram a identificação dos bens. $\mathrm{O}$ diagnóstico realizado pelos alunos demonstrou que as instituições eram carentes em seus processos administrativos. A contribuição dos alunos foi positiva para as duas partes (alunos e instituições/comunidade locais).

Os alunos puderam discutir com os representantes das instituições (associação e organização não governamentais) a importância dos controles e se sentiram úteis ao saber que suas ações podem contribuir para um melhor aproveitamento dos recursos gerando maiores benefícios para a sociedade. Os alunos identificaram que as instituições não realizavam controles no recebimento de doações (dinheiro, computador e móveis); na conferência de contracheques e dos bens patrimoniais; dentre outros. Após identificar a ausência dos controles, os alunos debateram e elaboraram sugestões ou soluções para as instituições beneficiadas. As sugestões e soluções consideradas viáveis foram mencionadas no relatório final entregue ao professor e posteriormente às instituições.

\section{CONSIDERAÇÕES FINAIS}

A adoção da disciplina PAS não garante a satisfação de todos os alunos e professores e nem a colocação do discente no mercado de trabalho, pois, depende da dedicação e compreensão dos envolvidos. Contudo, na disciplina os alunos são instigados a aprender, a investigar e a selecionar informação relevante, a integrar e aplicar conhecimentos, a analisar e sintetizar, a trabalhar em grupo, a ouvir e se expressar, a argumentar e defender pontos de vista, a fazer e a aceitar críticas, a verificar o quanto sabem e a identificar suas necessidades pessoais de aprendizagem.

Outro aspecto relevante neste processo é a contribuição para a formação cidadã. Apesar dessas instituições beneficiadas não visarem o lucro, elas precisam ter uma boa gestão para melhor aproveitamento dos recursos e consequentemente maiores benefícios para a sociedade. A adoção dos controles internos e a apuração dos custos nessas instituições do terceiro setor proporcionam uma sustentabilidade econômica conduzindo à continuidade de suas operações e ao cumprimento de suas missões. Assim, a comunidade local se beneficia, com o aproveitamento máximo dos recursos dessas instituições do terceiro setor e com a ampliação das ações sociais.

A disciplina descrita neste estudo pode ser considerada um caso de ensino de sucesso; uma vez que existe uma evolução na desenvoltura dos alunos e um aprendizado com a elaboração do relatório final. Podendo ser confirmado também pela continuidade da disciplina no curso de Ciências Contábeis e pelo interesse das instituições beneficiadas em contratar alunos para permanecer executando os controles internos propostos. 
Para o docente é o início de um novo caminho, diferente da aprendizagem tradicional, a Aprendizagem Significativa. É verdadeiramente um desafio, posto que a disciplina é construída ao longo do semestre pelos discentes e pelo docente. Não se sabe ao certo o que está por vir e é isso que se assemelha com a realidade do mercado de trabalho.

Os resultados aqui encontrados não podem ser generalizados, dado que se trata de um estudo de caso. Nesse sentido, propõe-se novos estudos sobre a aplicação da teoria da Aprendizagem Significativa em um contexto mais amplo, inserindo a disciplina PAS em outras universidades. Seria também interessante considerar a inserção da disciplina PAS em outros cursos, buscando contribuir para a formação cidadã dos alunos.

\section{REFERÊNCIAS}

Ausubel, D. P. (1963). The psychology of meaningful verbal learning. New York: Grune \& Stratton.

Barroso, J. (2005). O Estado, a educação e a regulação das políticas públicas. Educação \& Sociedade, 26(92), 725-751.

Behrens, M. A. (2009). Paradigmas educacionais e a prática pedagógica. Curitiba: Mimeo.

Biavatti, V. T., Mazzuco, M. A. S., \& Wronski, P. G. (2018). Percepção dos alunos de Ciências Contábeis quanto à aplicação de diálogos sucessivos no ensino. Revista Panorâmica online, 24.

Bledsoe, K. E., \& Flick, L. (2012). Concept development and meaningful learning among electrical engineering students engaged in a problem-based laboratory experience. Journal of Science Education and Technology, 21(2), 226-245.

Brandão, C. A. L. (2008). As profissões do futuro. Belo Horizonte: UFMG.

Brunstein, J., \& Miguel, L.A.P. (2007) Aprendizagem Significativa, memorização compreensiva e funcionalidade do conhecimento: reflexões sobre casos para ensino como trabalho de conclusão de curso no ensino superior. Anais do Encontro de Ensino e Pesquisa em Administração e Contabilidade, Recife, PE, Brasil.

Carvalho, A. C. B. D. D., Porto, A. J. V., \& Belhot, R. V. (2001). Aprendizagem Significativa no ensino de engenharia. Revista Produção 11(1), 81-90.

Conselho Nacional De Educação. (2003). Parecer CNE/CES nº 67, de 11 de março de 2003, Referencial para as Diretrizes Curriculares Nacionais - DCN dos Cursos de Graduação. Diário Oficial da União, Brasília, DF. Disponível em: < https://www.google. $\mathrm{com} / \mathrm{url}$ ? sa=t\&rct=j\&q=\&esrc=s\&source=web\&cd=1\&ved=2ahUKEwjg_Pm0yJbkAhVpGbkGHXyLDHsQFjAAegQIABAC\&url=http\%3A\%2F\%2Fportal.mec.gov.br\%2Fcne\%2Farquivos\%2Fpdf\%2FCES0067.pdf\&usg=AOvVaw1rY5DWV_R3g3zs4jL1NZn1>. Recuperado em 22 de ago de 2019.

Escrivão Filho, E., \& Ribeiro, L. R. C. (2008). Inovando no ensino de administração: uma experiência com a Aprendizagem Baseada em Problemas (PBL). Cadernos EBAPE. BR, 1-9.

Esteban-Guitart, M., Serra, J. M., \& Vila, I. (2017). Informationalism and informalization of learnings in 21st century. A qualitative study on meaningful learning experiences. Social and Education History, 6(1), 1-25.

Freire, P. (1996). Pedagogia da autonomia: saberes necessários à prática docente. São Paulo: Paz e Terra, 25.

Fronza, F. L. (2009). Diretrizes curriculares nacionais: mudanças no ensino superior? Dissertação de mestrado, Universidade do Vale do Itajaí, Santa Catarina, SC, Brasil.

Guimarães, M. L. F., Cittadin, A., Giassi, D., Guimarães Filho, L. P., \& Bristot, V. M. (2016). Reflexos do uso de metodologias ativas no ensino da contabilidade de custos. ABCustos, 11(3).

Haguete, T. M. F. (2003). Metodologias qualitativas na sociologia. Petrópolis: Vozes, 10 ed.

Marks, A., \& McIntosh, J. (2006). Achieving meaningful learning in health information management students: the importance of professional experience. Health Information Management Journal, 35(2), 14-22.

Marques, L., \& Praia, J. F. (2000). Os mapas de conceitos: Instrumentos para uma Aprendizagem Significativa. Actas do III Encontro Internacional sobre Aprendizagem Significativa, Universidade Aberta, Lisboa, 3, 343-350.

Martins, G. D. A., \& Lintz, A. (2007). Guia para elaboração de monografias e trabalho de conclusão de curso. São Paulo: Atlas, 2000. $108 \mathrm{p}$.

Martins, D. B., Espejo, M. M. S. B., \& Frezatti, F. (2015) Problem-based learning no ensino de contabilidade gerencial: relato de uma experiência brasileira. Revista de Educação e Pesquisa em Contabilidade, 9(4), 430- 452.

Menezes, E. T. D., \& Santos, T. H. D. (2002). DCNs (Diretrizes Curriculares Nacionais). Dicionário Interativo da Educação Brasileira-EducaBrasil. São Paulo: Midiamix Editora.

Merriam, S. B. (2002). Qualitative research in practice: Examples for discussion and analysis. Jossey-Bass Inc Pub.

Moreira, M. A., \& Masini, E. F. S. (2002). Aprendizagem Significativa: a teoria de David Ausubel. (2. ed.) São Paulo: Centauro.

Oliveira, L. S. (2004). Tratado de Metodologia Cientifica, Projetos de Pesquisas, TGI, TCC, Monografias, Dissertações e Teses. São Paulo: Pioneira Thomson Learning. 
Pereira, I. V., \& Silva, C. A. T. (2018). Aprendizagem cooperativa como estratégia de ensino para a contabilidade: habilidades intelectuais da taxonomia do domínio cognitivo. Revista Ambiente Contábil, 10(1), 54-70.

Santos, R. V. (1999). Modelagem de sistemas de custos. Revista do Conselho Regional de Contabilidade de São Paulo. São Paulo, 7, 62-74.

Santos, J. C. F. (2008). O papel do professor na promoção da Aprendizagem Significativa. Disponível em: http://www.pedagogia.com. $\underline{\mathrm{br} / \text { artigos/aprendizagemsig/index.php?pagina }=0}$. Acesso em 10/jun de 2018.

Vasconcelos, Y. L., \& Araújo, R. H. M. (2017) Emprego da técnica de mapas conceituais em disciplinas de contabilidade com abordagem gerencial. Revista Ambiente Contábil, 9(1), 117-143.

Zuffo, D., \& Behrens, M. A. (2009). Paradigmas educacionais: desafios e oportunidades para o século XXI. In: Encontro Sul Brasileiro de Psicopedagogia. EDUCERE - Anais do Congresso Nacional de Educação, Curitiba, PR, Brasil. 